\title{
The Development of Constructional Drawing Symbol E-Game Phase I
}

\author{
Lecturer Inthira Kampeera ${ }^{1}$ Lecturer Ekkachai Kopolrat ${ }^{2}$ \\ ${ }^{1}$ Faculty of Industrial Education and Technology \\ King Mongkut's University of Technology Thonburi, Bangkok, Thailand \\ jinthira@gmail.com \\ ${ }^{2}$ Sakonnakhon Technical College, Sakonnakhon, Thailand \\ ekachai@gmail.com
}

\begin{abstract}
The purpose of this research was to Constructional Drawing Symbol by EGame multimedia development are to be a useful media for constructional drawing student in vocational certificate majoring civil engineering to practice and get more understanding about efficiently applying. In addition to enjoy with constructional drawing symbol game that are included three of E-courseware 1) start with content explanation and the meaning of each symbol in constructional drawing 2) The game that players have to remember the differences of each symbol because some symbols have the same meaning, but they have the other different meanings in some constructional drawing issue 3) the memorize game that players have to complete the symbol images. The researcher got a good result (3.57) of satisfied test from 40 freshmen of vocational certificate majoring civil engineering.
\end{abstract}

Keywords: multimedia, E-courseware, Egame, Constructional Drawing Symbol.

\section{Introduction}

In Thailand Vocational certificate Educational majoring civil engineering learning and teaching, construction understanding skill is needed. Student who has learnt about how to draw and understand the construction will have more advantage than others in the way for being civil engineer. Everybody knows that the constructional knowledge, especially the symbol knowledge, is the basic knowledge for presenting the civil engineering meaning. However, learning about constructional symbol and methods for applying each kind of constructions to real situation is not easy.

It is interesting that whenever the students have free time, they always spend it for playing computer games, and from that reason the researcher try to develop the useful program in a pattern of games for teaching. The student can enjoy practicing, and also improving their knowledge. This game will motivate the student to develop the constructional drawing skill. The game will be available for students every time and everywhere that has a computer which operates beneath Microsoft Windows XP and Macromedia Flash Player.

The main purpose of constructional drawing symbol E-Game multimedia development is to improve both teaching and learning about constructional drawing and understanding to help the student enjoy learning constructional symbol. The student can guess new symbols from constructions that were set in the game. Constructional drawing symbol E-Game multimedia development 
phase I was operated with freshmen of vocational certificate majoring civil engineering.

\section{The Research Methods}

To study about the pattern of game for teaching

To create the stories and the patterns

To create contents and exercises

To create the multimedia in the pattern of game for practicing constructional symbol usage skill from following program, Macromedia Flash 8 / Adobe Photoshop 7 / Adobe Illustrator CS.

\section{The Results}

The result of Constructional drawing symbol E-Game multimedia development.

The program is included with three Ecourseware, one is symbol explanation, and others are game activities.

Activity 1, start with explaining the content and meanings of constructional drawing symbol.

Activity 2 memorize game, the players have to remember differences between each similar symbol, but use for different construction.

Activity 3, practicing game that the players have to complete correct answer with defined constructions. After the correct answer is put with the correct construction, the player will hear sound of clapping hand, but if the answer is wrong, the game will let players to change the answer. The game will be completed when players do every exercises, and a scoring chart will be shown.

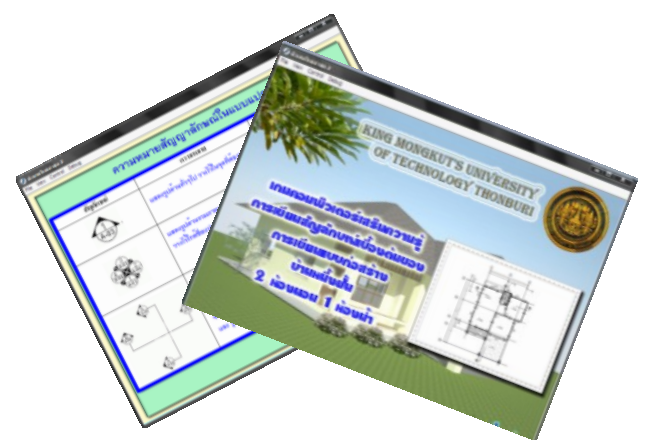

Fig. 1: Activity 1.

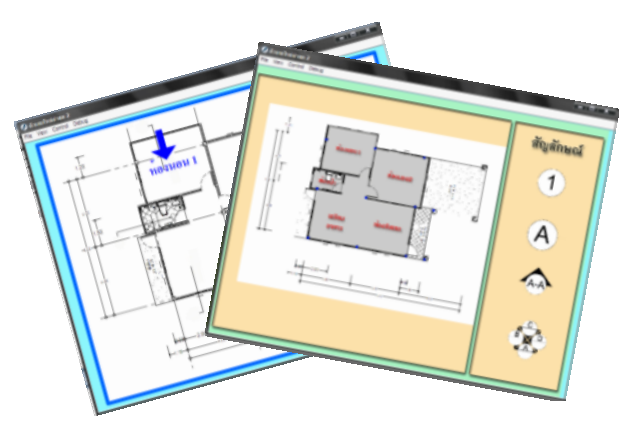

Fig. 2: Activity 2.

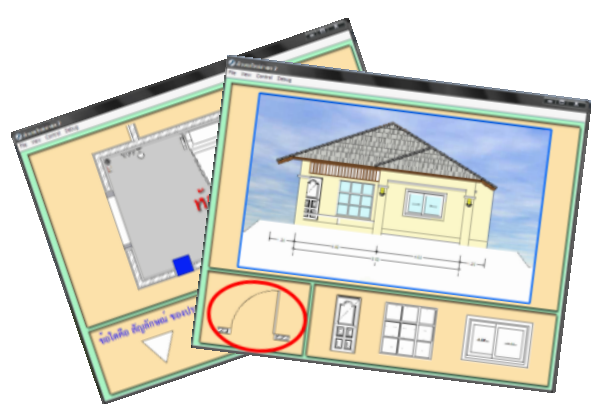

Fig. 3: Activity 3.

This program is appropriated with basic constructional drawing student in vocational certificate, and each exercise has different constructional symbols 
- The researcher has used this program with 40 freshmen of vocational certificate majoring civil engineering at least an hour.

- 45 percentages decided this is useful program with average point 3.92

- 44 percentages decided this game is interesting with average point 3.63

- 35 percentages decided this game is not different from other normal games with average point 3.47

- 42 percentages decided level of this game is appropriated with average point 3.57

The overall result is good with the average point 3.57 and many suggestions for development. All of them bring us to the next version of this game

\section{Discussion}

The researcher supports Constructional Drawing Symbol E-Game Phase II will be developed for in-creasing potentials of operating and numbers of game's style to be the media for better teaching.

\section{References}

[1] K.Indrambarya, "The Development of Word Factory E-Game Phase I Version 2.1," Proc. of 46th Kasetsart University Annual Conference: Education, Humanities and Social Sciences, Economics and Business Administration, Agricultural Extension and Home Economics, availble[November 29, 2012] http://www.lib.ku.ac.th/KUCONF/dat a51/KC4613002.pdf.

[2] K. Mead, "Game-based Learning and Intrinsic Motivation" Unpublished manuscript, available[November 25, 2012] http://www.alice.org/publications/Tea ching Objects first InIntroductory ComputerScience.pdf

[3] M. Prensky, "Digital Game based learning”, New York: McGraw-Hill, 2001.

[4] N. Sugianto, "An Implementation of Game-Based Learning using Alice Programming Environment", The Eighth International Conference on eLearning for Knowledge-Based Society, 23-24 February 2012, Thailand 